DOI: $12737 / 25207$

УДК 674.613

ОПРЕДЕЛЕНИЕ ПРЕДЕЛЬНОЙ НАСЫЩЕННОСТИ ДРЕВЕСНЫМИ ПЛИТАМИ ЖИЛЫХ ПОМЕЩЕНИЙ

доктор технических наук, профессор Е. М. Разиньков ${ }^{1}$

О. С. Воропаев ${ }^{1}$

Н. С. Киев ${ }^{1}$

1 - ФГБОУ ВО «Воронежский государственный лесотехнический университет имени Г.Ф. Морозова»,

г. Воронеж, Российская Федерация

Одним из актуальных вопросов применения в жилых помещений мебели является определение ее предельной (допустимой) насыщенности в помещениях с тем, чтобы в воздухе этих помещений выделение вредных для человека веществ не превышало предельно-допустимого уровня (предельно- допустимой концентрации - ПДК). Известно, что при использовании корпусной мебели из древесных плит (древесно-стружечных ДСтП, древесно-волокнистых - ДВП, плит МДФ) таким веществом является формальдегид. В настоящее время Минздравом РФ установлена ПДК формальдегида в воздухе на уровне $0.01 \mathrm{Mr} / \mathrm{M}^{3}$. Целью настоящей работы являлось определение предельной насыщенности древесными плитами объема жилого помещения при условии, что в помещении выделение формальдегида из плит не будет превышать установленного Минздравом ПДК. Такое определение предельной насьщенности (Пн, $\mathrm{m}^{2}$ плит/ $\mathrm{m}^{3}$ воздуха помещения) производили по выведенной нами ранее формуле. Расчеты были произведены для мебели (корпусной мебели, столов, кроватей щитовой конструкции, мебели для сидения и лежания, кроватей с мягкими спинками и элементами), напольных покрытий и стеновых панелей. В результате было установлено, что, например, при использовании ДСтП класса эмиссии формальдегида Е1 в конструкциях корпусной мебели, столов, кроватей щитовой конструкции величина Пн при $\mathrm{H}_{\text {исп }}$ равной $1.0 \mathrm{~m}^{2} / \mathrm{M}^{3}$ воздуха (насыщенность плитами объема воздуха при их испытании камерным методом) и при ПДК=0.01 $\mathrm{M \Gamma} / \mathrm{M}^{3}$ составляет $4.03 \mathrm{~m}^{2} /$ Комнату, а при ПДК=0.124 мг $/ \mathrm{M}^{3}$ (принятой странами-участниками ВТО и Всемирной организацией здравоохранения) она уже будет составлять $50.05 \mathrm{~m}^{2} /$ комнату. При использовании плит того же класса эмиссии, и при том же значении Нисп, при ПДК=0,01 мг $/ \mathrm{m}^{3}$ величина Пн составляет $6.25 \mathrm{~m}^{2} /$ комнату, то при ПДК $=0.124 \mathrm{м} / \mathrm{M}^{3}$ она уже будет составлять $77.63 \mathrm{~m}^{2} /$ комнату. При использовании ДСтП класса Е1 в конструкциях мебели для сидения и лежания, кроватей с мягкими спинками и элементами величина Пн при $\mathrm{H}_{\text {исп }}$ равном $0.3 \mathrm{~m}^{2} / \mathrm{m}^{3}$ воздуха и при ПДК $=0.01 \mathrm{мг} / \mathrm{M}^{3}$

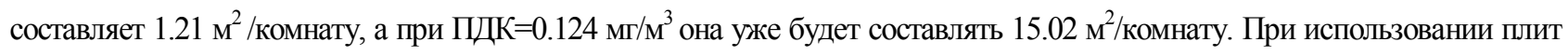
того же класса эмиссии, и при том же значении $\mathrm{H}_{\text {ип }}$ при ПДК $=0.01 \mathrm{M} / \mathrm{M}^{3}$ величина Пн составляет $1.88 \mathrm{~m}^{2} /$ комнату, то при ПДК $=0.124 \mathrm{Mr} / \mathrm{M}^{3}$ она уже будет составлять $23.45 \mathrm{~m}^{2} /$ комнату.

Ключевые слова: предельная насыщенность объема воздуха помещения, формальдегид, древесностружечная плита.

\title{
THE DEFINITION OF THE LIMIT OF SATURATION WITH WOOD PLATES FOR DOMESTIC PREMISES
} DSc in Engineering, Professor E. M. Razinkov ${ }^{1}$

\section{O. S. Voropaev ${ }^{1}$}

N. S. Kiev ${ }^{1}$

1 - Federal State Budget Education Institution of Higher Education «Voronezh State University of Forestry and Technologies named after G.F. Morozov», Voronezh, Russian Federation

\section{Abstract}

One of the topical issues of the application of furniture in domestic premises is defining its limiting (maximum) saturation in the premises so that the air in these premises, the allocation of harmful substances does not exceed the maximum allowable level (maximum permissible concentrations - MPC). It is known that in using furniture of wood-based panels (particle Board, Chipboard, wood fiber, MDF) this substance is formaldehyde. Currently, the MoH established the formaldehyde MPC in the air at the level of $0.01 \mathrm{mg} / \mathrm{m}^{3}$. The aim of this work was to determine the limit of saturation with the wood plates in premises, pro- 


\section{Деревопереработка. Химические технологии}

vided that indoor formaldehyde emissions from plates will not exceed the established by the Ministry of health MPC. This definition of the limit of saturation ( $\mathrm{Ls}, \mathrm{m}^{2}$ of plates $/ \mathrm{m}^{3}$ of the premises air) was performed according to our previously derived formula. Calculations were made for furniture (cabinet furniture, tables, beds of panel design, furniture for sitting and lying, beds with soft headboards and elements), floor coverings and wall panels. In the result, it was found that, for example, when using chipboard of E1 formaldehyde emission class in designs of furniture, tables, beds of panel construction value of Ls when the $\mathrm{I}_{\mathrm{ISP}}$ is $1.0 \mathrm{~m}^{2} / \mathrm{m}^{3}$ of air (saturation of the volume of air with plates in their testing by chamber method) and MPC $=0.01 \mathrm{mg} / \mathrm{m}^{3}$ is $4.03 \mathrm{~m}^{2}$ /room, and when $\mathrm{MPC}=0.124 \mathrm{mg} / \mathrm{m}^{3}$ (adopted by the countries-participants of the WTO and the World Health Organization) it will make $50.05 \mathrm{~m}^{2} /$ room. When using plates of the same emission class, and for the same value of $\mathrm{I}_{\mathrm{ISP}}$, when MPC $=0.01 \mathrm{mg} / \mathrm{m} 3$ Ls value is $6.25 \mathrm{~m}^{2} / \mathrm{room}$, when MPC $=0.124 \mathrm{mg} / \mathrm{m}^{3}$ it will make $77.63 \mathrm{~m}^{2} / \mathrm{room}$. When using E1 class chipboard panels in the construction of furniture for sitting and lying, beds with soft headboards and elements, Ls value in the $\mathrm{I}_{\mathrm{ISP}}$ is equal to $0.3 \mathrm{~m}^{2} / \mathrm{m}^{3}$ air and at $\mathrm{MPC}=0.01 \mathrm{mg} / \mathrm{m}^{3}$ is of $1.21 \mathrm{~m}^{2} / \mathrm{room}$, and when $\mathrm{MPC}=0.124 \mathrm{mg} / \mathrm{m}^{3}$ it will make $15.02 \mathrm{~m}^{2} / \mathrm{room}$. When using plates of the same emission class, and for the same value of $\mathrm{I}_{\mathrm{ISP}}$ at $\mathrm{Mac}=0.01 \mathrm{mg} / \mathrm{m}^{3} \mathrm{Ls}$ value is $1.88 \mathrm{~m}^{2} / \mathrm{room}$, when MPC $=0.124$ $\mathrm{mg} / \mathrm{m}^{3}$ it will make $23.45 \mathrm{~m}^{2} /$ room.

Keywords: Saturation limit of the air volume of the room, formaldehyde, chipboard.

По действующим на ДСтП стандартам (ГОСТ 10632-2014 и ГОСТ 32289-2013) [1, 2] предусмотрен выпуск неламинированных плит классов эмиссии формальдегида Е0,5; Е-1 и Е-2 (табл. 1) и ламинированых - классов Е-1 и Е-2 (табл. 2), для которых установлены свои нормы выделения фор- мальдегида при испытании плит перфораторным или камерным методами. Камерный метод является наиболее реальным с точки зрения моделирования реальных условий эксплуатации материалов в помещениях).

Таблица 1

Предельно-допустимые нормы выделения формальдегида в воздух в зависимости от класса эмиссии неламинированных ${ }^{*}$ ДСтП (ГОСТ 10632-2014)

\begin{tabular}{|c|c|c|}
\hline $\begin{array}{c}\text { Класс эмиссии } \\
\text { формальдегида }\end{array}$ & $\begin{array}{c}\text { Предельно допустимые нормы содержания формальде- } \\
\text { гида в плите, установленные перфораторным методом, } \\
\text { мг/100 г абс. сухой плиты }\end{array}$ & $\begin{array}{c}\text { Предельно допустимые нормы выделения формальдегида } \\
\text { из плиты в воздух, установленные методом испытания в } \\
\text { климатической камере, мг/м }{ }^{3} \text { воздуха }\end{array}$ \\
\hline E0,5 & До 4,0 включ. & До 0,08 включ. \\
\hline E1 & Св. 4,0 до 8,0 включ. & Св. 0,08 до 0,124 включ. \\
\hline Е2 & Св. 8,0 до 20,0 включ. & Св. 0,124 до 0,5 включ. \\
\hline
\end{tabular}

*неламинированные плиты - плиты, необлицованные пленками на основе термореактивных полимеров

Нормы выделения формальдегида из ламинированных *ДСтП по ГОСТ 32289-2013

\begin{tabular}{|c|c|c|c|}
\hline $\begin{array}{c}\text { Класс эмиссии плит по выде- } \\
\text { лению формальдегида }\end{array}$ & Метод испытания & $\begin{array}{c}\text { Норма выделения фор- } \\
\text { мальдегида }\end{array}$ & $\begin{array}{c}\text { Назначение испытаний (по ГОСТ } \\
16504)\end{array}$ \\
\hline \multirow{2}{*}{ E1 } & Камерный метод по ГОСТ 30255 & $\begin{array}{c}\text { До 0,124 мг/м }{ }^{3} \text { воздуха } \\
\text { включ. }\end{array}$ & $\begin{array}{c}\text { Квалификационные, контрольные } \\
\text { испытания }\end{array}$ \\
\hline & $\begin{array}{c}\text { Газоаналитический метод по ГОСТ } \\
32155\end{array}$ & До 3,5 мг/ м²·ч включ. & Производственный контроль \\
\hline \multirow{3}{*}{$\mathrm{E} 2$} & Камерный метод по ГОСТ 30255 & 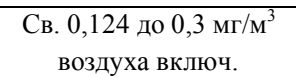 & \multirow{2}{*}{$\begin{array}{c}\text { Квалификационные, контрольные } \\
\text { испытания }\end{array}$} \\
\hline & $\begin{array}{c}\text { Газоаналитический метод по ГОСТ } \\
32155\end{array}$ & $\begin{array}{l}\text { Св. } 3,5 \text { до } 8,0 \mathrm{M \Gamma} / \mathrm{M}^{2} \cdot ч \\
\text { включ. }\end{array}$ & \\
\hline & $\begin{array}{c}\text { Газоаналитический метод по ГОСТ } \\
32155\end{array}$ & 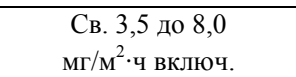 & Производственный контроль \\
\hline
\end{tabular}

*ламинированные плиты - плиты, необлицованные пленками на основе термореактивных полимеров 


\section{Деревопереработка. Химические технологии}

Пользуясь выведенной нами аналитической зависимостью (формула1) определения предельной насыщенности плитами объема помещения (комнаты), зная установленную Минздравом ПКД формальдегида в воздухе $[4,5]$, а также значения норм выделения формальдегида из плит из табл. 1 и 2 , можно будет определить искомую величину:

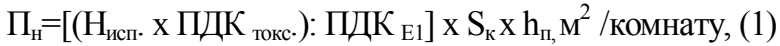
где $\Pi_{н}-$ предельная насыщенность плитами объема комнаты, м² ДСТП/комнату (искомая величина);

$\mathrm{H}_{\text {исп }}$ - насыщенность плитами объема воздуха при их испытании камерным методом, $\mathrm{M}^{2} / \mathrm{M}^{3}$ воздуха;

ПДК токс - ПДК формальдегида в воздухе жилых помещений (0,01 или 0,124 мг/м воздуха);

ПДК Е1 - допустимая норма выделения формальдегида из плит определенного класса эмиссии формальдегида, мг/M ${ }^{3}$ воздуха (для плит класса $\quad$ E1 0,124 , а для плит класса $E 0,5-0,08 \mathrm{Mr} / \mathrm{M}^{3}$ воздуха);

$\mathrm{S}_{\mathrm{K}}-$ площадь комнаты, $\mathrm{M}^{2}$ (примем равной 20 $\left.\mathrm{M}^{2}\right)$;

$\mathrm{h}_{\text {п }}$ - высота потолка комнаты, м (приме равной 2,5 M).

Произведем расчеты на примере использования в жильх помещениях мебели из ДСтП класса эмиссии формальдегида E0,5 и, для сравнения, класса эмиссии E1. Расчеты выполним для двух вариантов - при существующей норме ПКД формальдегида в воздухе $(0,01$ $\left.\mathrm{M \Gamma} / \mathrm{M}^{3}\right)$ и при ПДК $=0,0124 \mathrm{M \Gamma} / \mathrm{M}^{3}$, принятой в Европе и в странах ВТО в качестве безопасного уровня для че- ловека.

В расчетах определим значения предельной насыщенности плитами объема жилой комнаты в которой могуг быть размещена мебель различных групп.

При испытании плит в климатической камере (камерным методом) по ГОСТ 30255-2014 [3] насыщенность плитами объема воздуха $\left(\right.$ Нисп, $\left.\mathrm{m}^{2} / \mathrm{M}^{3}\right)$ должна находиться в пределах от 0,285 до $1,05 \mathrm{~m}^{2} / \mathrm{M}^{3}$ воздуха в зависимости от группы мебели (или напольных покрытий и стеновых панелей).

Полученные данные (табл. 3) показывают, что предельная насыщенность плитами объема помещения значительно увеличивается в зависимости от ПДК формальдегида в воздухе помещения (0,01 или 0,124 мг $/ \mathrm{M}^{3}$ воздуха). Это увеличение, естественно, будет более значительным при использовании в конструкциях мебели плит класса эмиссии Е0,5 по сравнению с плитами класса Е1.

Так, например, при использовании ДСтП класса эмиссии формальдегида Е1 в конструкциях корпусной мебели, столов, кроватей щитовой конструкции (при значении Нисп $=1,0 \mathrm{~m}^{2} / \mathrm{m}^{3}$ ) величина Пн при ПДК $=0,01 \mathrm{Mг} / \mathrm{M}^{3}$ составляет 4,03 $\mathrm{m}^{2} /$ комнату, а при ПДК $=0,124 \mathrm{мг} / \mathrm{M}^{3}$ она уже будет составлять $50,05 \mathrm{~m}^{2}$ /комнату. При использовании плит того же класса эмиссии, и при том же значении Нисп, при ПДК=0,01 мг $/ \mathrm{M}^{3}$ величина Пн составляет $6,25 \mathrm{~m}^{2} /$ комнату, то при ПДК $=0,124 \mathrm{мг} / \mathrm{M}^{3}$ она уже будет составлять $77,63 \mathrm{~m}^{2}$ /комнату. Как следует из этих данных при ПДК фор-

Таблица 3

Результаты расчетов величины предельной насыщенности плитами объема воздуха жилого помещения

\begin{tabular}{|c|c|c|c|c|c|c|c|}
\hline \multirow[t]{2}{*}{$\begin{array}{l}\text { Нисп, } \\
\mathrm{m}^{2} / \mathrm{m}^{3}\end{array}$} & \multirow[t]{2}{*}{$\begin{array}{c}\text { ПДК токс, } \\
\mathrm{m}^{2} / \mathrm{m}^{3}\end{array}$} & \multicolumn{2}{|c|}{$\begin{array}{c}\text { Норма выделения формальдегида } \\
\text { для плит классов, } \\
\text { м² }^{2}{ }^{3}\end{array}$} & \multicolumn{2}{|c|}{$\begin{array}{c}\text { Величина Пн в м² } / \text { комнату } \\
\text { для плит Е1 (с ПДК=0,01 и } \\
0,124 \text { мг } / \mathrm{M}^{3} \text { воздуха) }\end{array}$} & \multicolumn{2}{|c|}{$\begin{array}{c}\text { Величина Пн в м }{ }^{2} / \text { комнату } \\
\text { для плит Е0,5 (с ПДК=0,01 и } \\
0,124 \text { мг } / \mathrm{m}^{3} \text { воздуха) }\end{array}$} \\
\hline & & E1 & $\mathrm{E} 0,5$ & $\begin{array}{r}\text { ПДК= } \\
0,01\end{array}$ & $\begin{array}{c}\text { ПДК= } \\
0,124\end{array}$ & ПДК $=0,01$ & $\begin{array}{c}\text { ПДК= } \\
0,124\end{array}$ \\
\hline \multicolumn{8}{|c|}{ 1. Для корпусной мебели, столов, кроватей щитовой конструкции } \\
\hline 0,95 & 0,01 & 0,124 & 0,08 & 3,83 & 47,57 & 5,93 & 73,75 \\
\hline 1,00 & 0,01 & 0,124 & 0,08 & 4,03 & 50,05 & 6,25 & 77,63 \\
\hline 1,05 & 0,01 & 0,124 & 0,08 & 4,23 & 52,53 & 6,56 & 81,48 \\
\hline \multicolumn{8}{|c|}{ 2. Для мебели для сидения и лежания, кроватей с мягкими спинками и элементами } \\
\hline 0,285 & 0,01 & 0,124 & 0,08 & 1,15 & 14,28 & 1,78 & 22,11 \\
\hline 0,300 & 0,01 & 0,124 & 0,08 & 1,21 & 15,02 & 1,88 & 23,35 \\
\hline 0,315 & 0,01 & 0,124 & 0,08 & 1,27 & 15,77 & 1,97 & 24,47 \\
\hline \multicolumn{8}{|c|}{ 3. Для напольных покрытий и стеновых панелей } \\
\hline 0,38 & 0,01 & 0,124 & 0,08 & 1,53 & 19,00 & 2,38 & 29,56 \\
\hline 0,40 & 0,01 & 0,124 & 0,08 & 1,61 & 20,00 & 2,50 & 31,05 \\
\hline 0,42 & 0,01 & 0,124 & 0,08 & 1,69 & 20,99 & 2,63 & 32,66 \\
\hline
\end{tabular}


мальдегида, равной 0,124 мг/ $\mathrm{M}^{3}$ воздуха, предельная насыщенность плитами объема комнаты намного увеличивается, по сравнению с ПДК, равной $0,01 \mathrm{мг} / \mathrm{M}^{3}$ воздуха.

На рис. 1 - 3 представлены зависимости Пн = $\mathrm{F}($ Нисп) для двух групп мебели, а также для напольных покрытий и стеновых панелей, которые наглядно иллюстрируют приведенные в табл. 1 значения.

Таким образом, пользуясь соответствующими данными, как показано на вышеприведенном примере, можно определить предельную насыщенность плитами жилой комнаты для достижения установленной Минздравом ПДК формальдегида в воздухе.

Зная общую площадь плит в конструкции мебели можно уже принять решение сколько можно будет разместить в комнате мебели для исключения вредного воздействия формальдегида на человека.

Для снижения выделения формальдегида из ДСтП существует ряд методов $[6,7,8,9,10,11]$ используя которые в технологии плит можно добиться увеличения насыщенности плитами (или мебелью из плит) объема жилого помещения.

Выводы:

1.Определение предельной насыщенности древесно-стружечными плитами объема жилых помещений показало, что при использовании плит класса эмиссии формальдегида Е1 в конструкциях корпусной мебели, столов, кроватей щитовой конструкции величина предельной насыщенности при $\mathrm{H}_{\text {исп }}$ равной $1,0 \mathrm{~m}^{2} / \mathrm{m}^{3}$ воздуха (насыщенность плитами объема воздуха при их испытании камерным

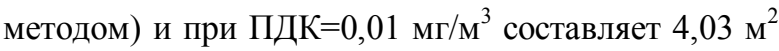

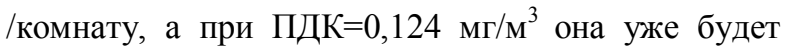
составлять 50,05 м²/комнату.

При использовании плит того же класса эмиссии, и при том же значении Нисп, при ПДК $=0,01 \mathrm{мг} / \mathrm{M}^{3}$ величина Пн составляет $6,25 \mathrm{~m}^{2}$

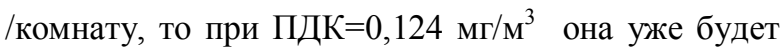
составлять 77,63 м²/комнату.

При использовании ДСтП класса Е1 в конст-

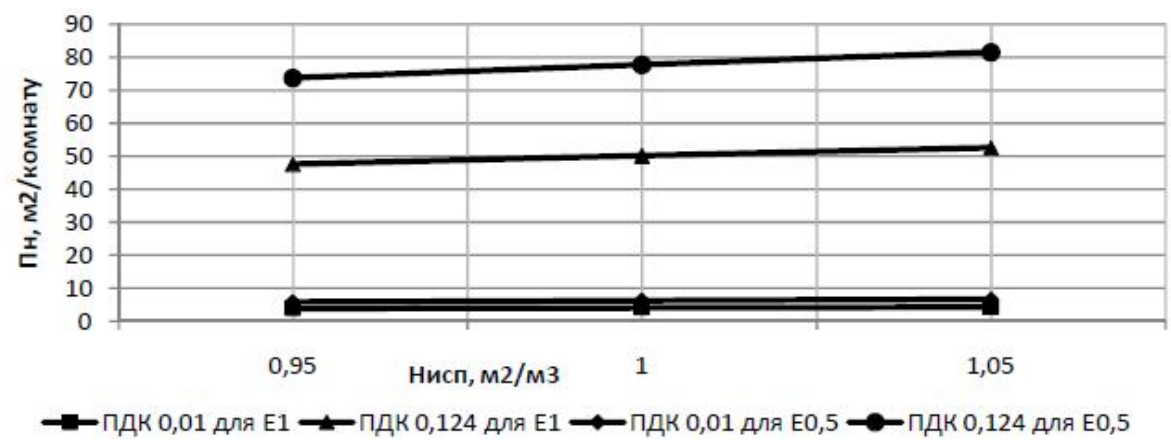

Рис. 1. Зависимость предельной насыщенности плитами Е1 и Е0,5 объема комнаты от насыщенности ими объема воздуха при испытании камерным методом для корпусной мебели, столов, кроватей щитовой конструкции при ПДК формальдегида 0,01 и 0,124 мг/м³ воздуха

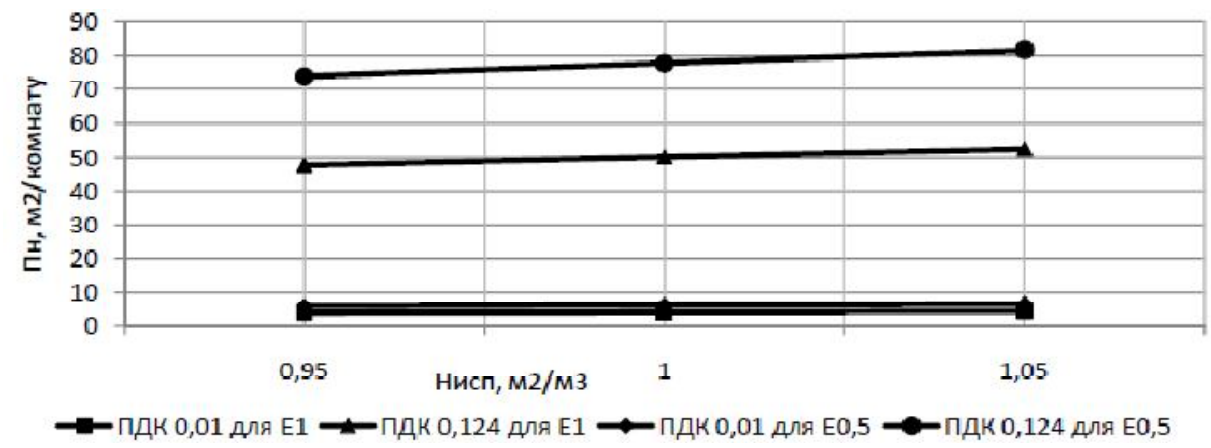

Рис. 2. Зависимость предельной насыщенности плитами Е1 и Е0,5 объема комнаты от насыщенности ими объема воздуха при испытании камерным методом применительно к мебели для сидения и лежания, кроватей с мягкими спинками и элементами при ПДК формальдегида 0,01 и 0,124 мг/м³ воздуха 


\section{Деревопереработка. Химические технологии}

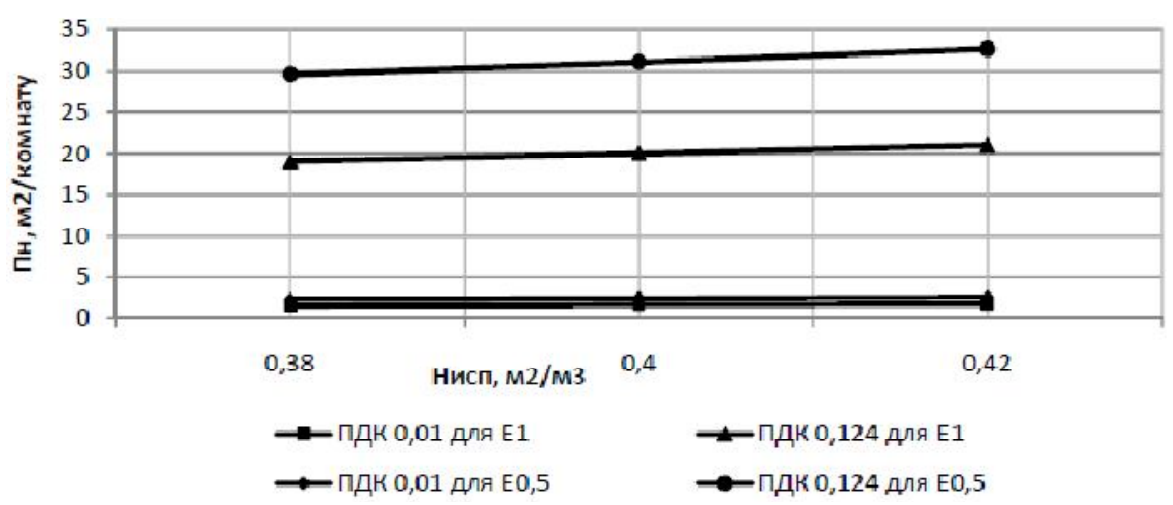

Рис. 3 Зависимость предельной насыщенности плитами Е1 и Е0,5 объема комнаты от насыщенности ими объема воздуха при испытании камерным методом для напольных покрытий и стеновых панелей при ПДК формальдегида 0,01 и $0,124 \mathrm{Mг} / \mathrm{M}^{3}$ воздуха

рукциях мебели для сидения и лежания, кроватей с мягкими спинками и элементами величина Пн при $\mathrm{H}_{\text {исп }}$ равном $0,3 \mathrm{~m}^{2} / \mathrm{m}^{3}$ воздуха и при ПДК $=0,01 \mathrm{мг} / \mathrm{M}^{3}$ составляет $1,21 \mathrm{~m}^{2} /$ комнату, а при ПДК $=0,124 \mathrm{мг} / \mathrm{M}^{3}$ она уже будет составлять $15,02 \mathrm{~m}^{2} /$ комнату. При использовании плит того же класса эмиссии, и при том же значении $\mathrm{H}_{\text {исп }}$ при ПДК $=0,01 \mathrm{мг} / \mathrm{M}^{3}$ величина Пн составляет $1,88 \mathrm{~m}^{2} /$ комнату, то при ПДК $=0,124$ мг/ $\mathrm{M}^{3}$ она уже будет составлять 23,45 $\mathrm{m}^{2}$ /комнату.

2.Зная общую площадь плит в конструкции, например, мебели можно уже принять решение сколько можно будет разместить в комнате мебели для исключения вредного воздействия формальдегида на человека.

\section{Библиографический список}

1. ГОСТ 10632-2014. Плиты древесно-стружечные. Характеристики [Текст]

2.ГОСТ 32289-2013. Плиты древесно-стружечные, облицованные пленками на основе термореактивных полимеров. Технические условия (EN 438-2:2005, NEQ [Текст]

3.ГОСТ 30255-2014. Мебель, древесные и полимерные материалы [Текст]. Метод определения выделения формальдегида и других вредных летучих химических веществ в климатических камерах

4.Гигиенические нормативы ГН 2.1.6.1338-03 (с изменениями на 12 января 2015 года) «Предельно допустимые концентрации (ПДК) загрязняющих веществ в атмосферном воздухе населенных мест» [Текст]. Утверждены государственным санитарным врачом Российской Федерации.

5.ГОСТ 12.1.007. Система стандартов безопасности труда. Вредные вещества [Текст]. Классификация и общие требования безопасности

6. Experimental study on flexural behavior of glulam and laminated veneer lumber beams [Text] / Liu, W. Q. Yang, H. F. Dong, F. Q. [et al.] // Modern bamboo structures: Conference: 1st International Conference on Modern Bamboo Structures Location: Hunan Univ, Changsha, PEOPLES R CHINA Date: OCT 28-30, 2007. - 2008. - pp. 159-169.

7. Laminated veneer lumber from Rowan (SorbusaucupariaLipsky) [Text] / H. S. Kol, H. Keskin, S. Korkut, T. Akbulut // African journal of agricultural research - OCT. - 2009. - pp. 1101-1105.

8. Справочник мебельщика [Текст] : учеб. пособие / Б. И. Артамонов [и др.] ; под ред. В. П. Бухтиярова. 3-е изд., перераб. - М., 2005. - 600 с.

9. Разиньков, Е.М. Снижение токсичности древесных плит и клееных материалов [Текст] : монография, [Текст] / Е.М. Разиньков, Т.Л. Ищенко Опубликовано 16.01.2013.Palmarium Academic PublishingIs a trademark of:AV Akademikerverlag GmbH Co. KGHeinrich-Bocking-Str. 6-8-66121, Saarbrucken.Germany

10.Разиньков, Е.М. Промышленное производство малотоксичных древесностружечных плит [Текст] / Е.М. Разиньков // Природопользование: ресурсы, технической обеспечение. Выпуск 4: сборник научных трудов / ВГЛТА. - Воронеж, 2009. - С. 121-128. 


\section{Деревопереработка. Химические технологи}

\section{References}

1. GOST 10632-2014. Plity drevesno-struzhechnye. Harakteristiki [State Standard. Plates are wood-shaving. Specifications] (In Russian).

2. GOST 32289-2013. Plity drevesno-struzhechnye, oblicovannye plenkami na osnove termoreaktivnyh polimerov. Tehnicheskie uslovija (EN 438-2:2005, NEQ) [State Standard. Plates are wood-shaving, revetted with films on the basis of thermoreactive polymers. Specifications (EN 438-2:2005, NEQ] (In Russian).

3. GOST 30255-2014. Mebel', drevesnye i polimernye materialy Metod opredelenija vydele-nija formal'degida i drugih vrednyh letuchih himicheskih veshhestv v klimaticheskih kamerah [Furniture, wood and polymeric materials. A method of definition of release of formaldehyde and other harmful flying chemicals in climatic chambers] (In Russian).

4. Gigienicheskie normativy GN 2.1.6.1338-03 (s izmenenijami na 12 janvarja 2015 goda) «Predel'no dopustimye koncentracii (PDK) zagrjaznjajushhih veshhestv v atmosfernom vozduhe naselennyh mest» [Hygienic standards of GN 2.1.6.1338-03 (with changes for January 12, 2015) "The Maximum Permissible Concentration (MPC) of the polluting substances in atmospheric air of the inhabited places". Are approved as the state health officer of the Russian Federation]. (In Russian).

5. GOST 12.1.007. Sistema standartov bezopasnosti truda. Vrednye veshhestva. Klassifikacija i obshhie trebovanija bezopasnosti [Occupational safety standards system. Harmful substances. Classification and general safety requirements] (In Russian).

6. Liu W.Q. Yang H.F. Dong F.Q. [et al.] Experimental study on flexural behavior of glulam and laminated veneer lumber beams. Modern bamboo structures: Conference: 1st International Conference on Modern Bamboo Structures Location: Hunan Univ, Changsha, peoples r china Date: OCT 28-30, 2007, 2008, pp. 159169.

7. Kol H.S., Keskin H., Korkut S., Akbulut T. Laminated veneer lumber from Rowan (SorbusaucupariaLipsky). African journal of agricultural research. OCT 2009, pp.1101-1105.

8. Artamonov B.I., Bukhtiyarov V.P., Velk A.A., Kuznetsov V.E., Novak G.K., Panova T.N. [i dr.] Spravochnik mebel'shchika [Reference book of the furniture maker]. Moscow, 2005, 600 p. (In Russian).

9. Razinkov E.M., Ishhenko T.L. Snizhenie toksichnosti drevesnyh plit i kleenyh materialov [Decrease in toxicity of wood plates and glued materials (monograph, Germany)] Palmarium Academic PublishingIs a trademark of:AV Akademikerverlag GmbH Co. KGHeinrich-Bocking-Str. 6-8-66121, Saarbrucken.Germany

10. Razinkov E.M. Promyshlennoe proizvodstvo malotoksichnyh drevesnostruzhechnyh plit [Industrial production of low-toxic wood chipboards] Prirodopol'zovanie: resursy, tehnicheskoj obespechenie [Environmental management: resources, technical providing]. Voronezh, 2009, pp 121-128. (In Russian).

\section{Сведения об авторе}

Разиньков Егор Михайлович - заведующий кафедрой механической технологии древесины ФГБОУ ВО «Воронежский государственный лесотехнический университет имени Г.Ф. Морозова», доктор технических наук, профессор, г. Воронеж, Российская Федерация; e-mail: mtd.vrn@mail.ru.

\section{Information about author}

Razinkov Egor Mikhaylovich - Head of the department of mechanical technology of wood Federal State Budget Education Institution of Higher Education «Voronezh State University of Forestry and Technologies named after G.F. Morozov», DSc in Engineering, Professor, Voronezh, Russian Federation; e-mail: mtd.vrn@mail.ru. 